\title{
Analysis of Electrical Properties Using the four point Probe Method
}

\author{
Richard S. Waremra ${ }^{1, *}$ and Philipus Betaubun ${ }^{2}$ \\ ${ }^{1}$ Department of Physics Education, Faculty of Teacher Training and Education, Musamus University, Merauke - \\ Indonesia \\ ${ }^{2}$ Department of Civil Enginering, Faculty of Enginer, Musamus University, Merauke - Indonesia
}

\begin{abstract}
There has been conducted Physics research on a material, that is, monitoring electric characteristic of a material using four-point probe method. This research measures current and voltage. The result is used to determine resistivity of a material. The research uses 2 samples, that is, chalk and charcoal. The result shows the resistivity of the sample in the form of bulk $(\mathrm{t}>\mathrm{s})$ for chalk has high resistivity on voltage of 6.6 Volt. Meanwhile, resistivity on thick sheet $(\mathrm{t}<\mathrm{s})$ has high resistivity on voltage of 7 Volt. On the charcoal material, large resistivity $(\mathrm{t}>\mathrm{s})$ is in 6 Volt, and on large resistivity $(\mathrm{t}<\mathrm{s})$ is in 6.6 Volt.
\end{abstract}

Keywords: current, four point probe, conductivity, resistivity, voltage

\section{Introduction}

Since 20 to 30 years ago, the temperature at the earth it is getting hotter because the sun long wave radiation infrared beam or heat waves) emitted by the earth trapped a thick coat of consisting of numerous gas, so as to cause heat could not be separated into space so that the temperature of the earth to warm up, it was when we were in the fetid one quadrillionth of a in glass houses. Hence, the incident one quadrillionth of a it is called as the greenhouse effect. Warming caused by greenhouse effect can be dirasakanoleh of the universe who the earth , so this incident also is called as global warming (ICRAF, 2016 ). The impact of the greenhouse effect also in taste in indonesia.

Four-point probe measurer (FPP) is a tool that is commonly used to measure resistivity value of a layer of an electronic material, that is, semi-conductor material such as silicon ( $\mathrm{Si}$ ), Germanium (Ge), Ballium Arsenide (GaAs), as well as metallic material in thin film (thin layer) that is used in electronic devices.

Like its name, this measurer is relied on 4 probes; 2 probes are for electric current and the 2 other ones are to measure voltage when they are applied to the material (sample). To determine and to review the characteristics of the material, the resistivity value needs to be measured for certain area and thickness. Some other parameters that can be obtained from material measurement using this tool is to know the type of doping of a semi-conductor material (positive and negative) and electronic mobility of a material.

In this practice, samples or materials used are chalk and charcoal. The purpose of this practice is to determine the resistivity and conductivity of a material on the samples in the form of bulk and thick sheet.

To monitor electric characteristics of a material, fourpoint probe method is often used (probe with four points). It is called four-point probe because there are four points that touched on the sample surface. Those four points (probes) is made lined in a straight line with the distance between probes is arranged in such a way, so that each of the probes has the same distance. A constant electric current is streamed along the sample through two outermost probes. If the sample has resistance, there will be a voltage drop when the current flows along the sample. The voltage change is measured through two inner probes. Electrical quantity that shows the quality of material conductivity, such as output voltage and output current, can be determined meticulously using four-point probe method.

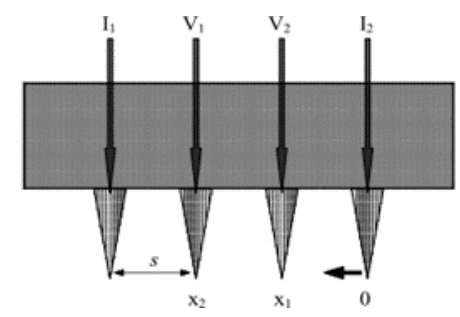

Fig. 1. FPP Scheme.

\subsection{Reistivity of Bulk Sample}

It is initially assumed that the tip of the probe is very small (infinitesimal) and the sample has a large dimension (semi-infinite). This bulk sample requires

* Corresponding author: rickywaremra@unmus.ac.id 
that the sample thickness $(\mathrm{t})$ be more than the distance between probes (s).

$$
\rho=2 \pi s(V / I)
$$

with conductivity is:

$$
\sigma=1 / \rho
$$

\subsection{Reistivity of thick sheet sample}

Different from bulk sample, this thick sheet requires that the sample thickness (t) should be less than the distance between probes ( $\mathrm{s}$ ). Because at the ends of the outer probe is the superstition of the current, then $\mathrm{R}=$ $\mathrm{V} / 2 \mathrm{I}$.

with conductivity is:

$$
\rho=\pi \mathrm{t} /(\operatorname{Ln} 2)(\mathrm{V} / \mathrm{I})
$$

$$
\sigma=1 / \rho
$$

\section{Methodology}

The methodology uses the ekploratif use of secondary data.In making the mitigation based on estimation carbon emissions the future use of looking forward with basic data on carbon emissions past (minimal) baseline. Basic data used to analyze emission levels past the map land data closing time series in 1990, 2000, 2005, 2010 and in 2014 and maps plans space pattern planning merauke 2010-2030 district year.Furthermore the data processed using software lumens ( the land use planning for low emission development strategy) using integrated approach and analysis of trade off which includes: planning sustainable development, planning use land, and action planning mitigation the overall.

This research uses equipment such as power supply, 2 pieces of multi-meters, cable pliers, ruler, beaker, and stirring solution. The sample used is a piece of $\mathrm{CaCO} 3$ (chalk), a piece of $\mathrm{C}$ (charcoal), $\mathrm{NaCl}$ (salt), and water.

Procedures:

1. The samples are divided into 3 equal lengths by making 2 segments where probe 2 and 3 are. The segment length is more than the thickness $(\mathrm{t}<\mathrm{s})$.

2. The samples are divided into 3 parts by placing 2 segments on the material which are shorter than their thickness $(\mathrm{t}>\mathrm{s})$.

3. Making a solution of $\mathrm{NaCl}$

4. Soaking the samples in the solution of $\mathrm{NaCl}$ for 15 minutes.

5. Assembling tools and materials as seen in the picture

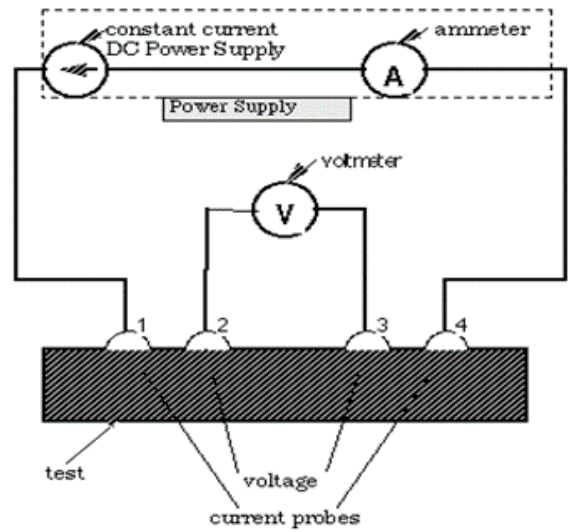

Fig. 2. FPP Circuit

6. Varying the input voltage on the sample.

7. Measuring the value of current and voltage in the circuit.

8. Data collection is repeated 3 times.

Calculating resistivity and conductivity of the material based on the equation above.

\section{Result and Discussion}

The result of the research and its analysis can be presented below.

\subsection{Resistivity of Bulk Sample}

It is initially assumed that the tip of the probe is very small (infinitesimal) and the sample has a large dimension (semi-infinite). This bulk sample requires that the sample thickness $(\mathrm{t})$ be more than the distance

\begin{tabular}{|c|c|c|}
\hline$V_{\text {power suplly }}$ & $\begin{aligned} & V(\text { Volt }) \\
\pm & \frac{0,1}{10} \times 10 \mathrm{~V}\end{aligned}$ & $\begin{array}{c}\text { I (Ampere) } \\
\pm \frac{25}{50} \times 50 \mu A\end{array}$ \\
\hline \multirow{3}{*}{$6 \mathrm{~V}$} & $0,1 \mathrm{~V}$ & $25 \times 10^{-6} \mathrm{~A}$ \\
\hline & $0,1 \mathrm{~V}$ & $26 \times 10^{-6} \mathrm{~A}$ \\
\hline & $0,1 \mathrm{~V}$ & $25 \times 10^{-6} \mathrm{~A}$ \\
\hline \multirow{3}{*}{$6,6 \mathrm{~V}$} & $0,25 \mathrm{~V}$ & $21 \times 10^{-6} \mathrm{~A}$ \\
\hline & $0,20 \mathrm{~V}$ & $16 \times 10^{-6} \mathrm{~A}$ \\
\hline & $0,20 \mathrm{~V}$ & $21 \times 10^{-6} \mathrm{~A}$ \\
\hline \multirow{3}{*}{$7 \mathrm{~V}$} & $0,4 \mathrm{~V}$ & $50 \times 10^{-6} \mathrm{~A}$ \\
\hline & $0,4 \mathrm{~V}$ & $40 \times 10^{-6} \mathrm{~A}$ \\
\hline & $0,4 \mathrm{~V}$ & $40 \times 10^{-6} \mathrm{~A}$ \\
\hline
\end{tabular}
between probes (s).

Table 1. The Measurement of Current (I) and Volt (V) for White Chalk (CaCo3)

Table 2. Resistivity $(\rho)$ and Conductivity $(\sigma)$ of the material

\begin{tabular}{|c|c|c|}
\multicolumn{2}{c|}{$\left(\mathrm{CaCo}_{3}\right)$} \\
\hline $\mathrm{V}_{\text {power suplly }}$ & $\rho(\Omega \mathrm{m})$ & $\sigma(\Omega \mathrm{m})$ \\
\hline \multirow{3}{*}{$6 \mathrm{~V}$} & 190,912 & $5,24 \times 10^{-3}$ \\
\cline { 2 - 3 } & 183,569 & $5,45 \times 10^{-3}$ \\
\cline { 2 - 3 } & 190,912 & $5,24 \times 10^{-3}$ \\
\hline \multirow{3}{*}{$6,6 \mathrm{~V}$} & 568,190 & $1,76 \times 10^{-3}$ \\
\cline { 2 - 3 } & 596,600 & $1,67 \times 10^{-3}$ \\
\cline { 2 - 3 } & 454,552 & $2,19 \times 10^{-3}$ \\
\hline \multirow{3}{*}{$7 \mathrm{~V}$} & 381,824 & $2,62 \times 10^{-3}$ \\
\cline { 2 - 3 } & 477,28 & $2,09 \times 10^{-3}$ \\
\cline { 2 - 3 } & 381,824 & $2,62 \times 10^{-3}$ \\
\hline
\end{tabular}




\subsection{Resistivity of Thick Sheet Sample}

Resistivity of bulk sample $(\mathrm{t}<\mathrm{s})$ with $\mathrm{t}=0.9 \mathrm{~cm}$ dan $\mathrm{s}=$ $1.72 \mathrm{~cm}$. The material used is $\mathrm{CaCO}_{3}$ (chalk). On the data result, it is seen the measurement result of current (I) and voltage (V), then the result of resistivity and conductivity of the material are presented as well.

Table 3. The Measurement of Current (I) and Voltage (V) for White Chalk $\left(\mathrm{CaCo}_{3}\right)$

\begin{tabular}{|c|c|c|}
\hline \multirow{2}{*}{$\mathrm{V}_{\text {power suplly }}$} & $\begin{array}{c}\mathrm{V}(\text { Volt }) \\
\mathbf{0 2} \times 10 \mathrm{~V}\end{array}$ & $\begin{array}{c}\text { I (Ampere) } \\
\mathbf{1 6}\end{array} \frac{\mathbf{1 6}}{\mathbf{5} 0} \times 2,5 \mathrm{AA}$ \\
\hline \multirow{3}{*}{$6 \mathrm{~V}$} & $0,2 \mathrm{~V}$ & $16 \rightarrow 0,8 \times 10^{-6} \mathrm{~A}$ \\
\cline { 2 - 3 } & $0,2 \mathrm{~V}$ & $15 \rightarrow 0,75 \times 10^{-6} \mathrm{~A}$ \\
\cline { 2 - 3 } & $0,2 \mathrm{~V}$ & $15 \rightarrow 0,75 \times 10^{-6} \mathrm{~A}$ \\
\hline \multirow{3}{*}{$6,6 \mathrm{~V}$} & $0,2 \mathrm{~V}$ & $16 \rightarrow 0,8 \times 10^{-6} \mathrm{~A}$ \\
\cline { 2 - 3 } & $0,1 \mathrm{~V}$ & $17 \rightarrow 0,85 \times 10^{-6} \mathrm{~A}$ \\
\cline { 2 - 3 } & $0,2 \mathrm{~V}$ & $16 \rightarrow 0,8 \times 10^{-6} \mathrm{~A}$ \\
\hline \multirow{3}{*}{$7 \mathrm{~V}$} & $0,4 \mathrm{~V}$ & $16 \rightarrow 0,8 \times 10^{-6} \mathrm{~A}$ \\
\cline { 2 - 3 } & $0,2 \mathrm{~V}$ & $11 \rightarrow 0,55 \times 10^{-6} \mathrm{~A}$ \\
\cline { 2 - 3 } & $0,2 \mathrm{~V}$ & $11 \rightarrow 0,55 \times 10^{-6} \mathrm{~A}$ \\
\hline
\end{tabular}

Table 4. Resistivity ( $\rho$ ) and Conductivity $(\sigma)$ for White Chalk $\left(\mathrm{CaCo}_{3}\right)$

\begin{tabular}{|c|c|c|}
\hline $\mathrm{V}_{\text {power suplly }}$ & $\rho(\Omega \mathrm{m})$ & $\sigma(\Omega \mathrm{m})$ \\
\hline \multirow{3}{*}{$6 \mathrm{~V}$} & $10.192,64$ & $9,81 \times 10^{-5}$ \\
\cline { 2 - 3 } & $10.872,15$ & $9,19 \times 10^{-5}$ \\
\cline { 2 - 3 } & $10.872,15$ & $9,19 \times 10^{-5}$ \\
\hline \multirow{3}{*}{$6,6 \mathrm{~V}$} & $10.192,64$ & $9,81 \times 10^{-5}$ \\
\cline { 2 - 3 } & $4.796,54$ & $2.08 \times 10^{-5}$ \\
\cline { 2 - 3 } & $10.192,64$ & $9,81 \times 10^{-5}$ \\
\hline \multirow{3}{*}{$7 \mathrm{~V}$} & $21.744,29$ & $4,59 \times 10^{-5}$ \\
\cline { 2 - 3 } & $14.825,65$ & $6,75 \times 10^{-5}$ \\
\cline { 2 - 3 } & $14.825,65$ & $6,75 \times 10^{-5}$ \\
\hline
\end{tabular}

\subsection{Resistivity of Bulk Sample}

Resistivity of bulk sample $(\mathrm{t}>\mathrm{s})$ with $\mathrm{t}=2.45 \mathrm{~cm}$ dan $\mathrm{s}$ $=1.67 \mathrm{~cm}$. The material used is $\mathrm{C}$ (charcoal). On the data result, it is seen the measurement result of current (I) and voltage (V), then the result of resistivity and conductivity of the material are presented as well.

Table 5. The Measurement of Current (I) and Voltage (V) for C (charcoal)

\begin{tabular}{|c|c|c|}
\hline \multirow{2}{*}{$\mathrm{V}_{\text {power suplly }}$} & $\begin{array}{c}\mathrm{V} \text { (Volt) } \\
\pm \frac{0,4}{10} \times 10 \mathrm{~V}\end{array}$ & $\begin{array}{c}\text { I (Ampere) } \\
\pm \frac{9}{50} \times 2,5 \mu \mathrm{A}\end{array}$ \\
\hline \multirow{3}{*}{$6 \mathrm{~V}$} & $0,4 \mathrm{~V}$ & $9 \rightarrow 0,4 \times 10^{-6} \mathrm{~A}$ \\
\cline { 2 - 3 } & $0,4 \mathrm{~V}$ & $9 \rightarrow 0,4 \times 10^{-6} \mathrm{~A}$ \\
\cline { 2 - 3 } & $0,4 \mathrm{~V}$ & $9 \rightarrow 0,4 \times 10^{-6} \mathrm{~A}$ \\
\hline \multirow{3}{*}{$6,6 \mathrm{~V}$} & $0,6 \mathrm{~V}$ & $15 \rightarrow 0,75 \times 10^{-6} \mathrm{~A}$ \\
\cline { 2 - 3 } & $0,6 \mathrm{~V}$ & $15 \rightarrow 0,75 \times 10^{-6} \mathrm{~A}$ \\
\cline { 2 - 3 } & $0,4 \mathrm{~V}$ & $15 \rightarrow 0,75 \times 10^{-6} \mathrm{~A}$ \\
\hline \multirow{2}{*}{$7 \mathrm{~V}$} & $0,6 \mathrm{~V}$ & $17 \rightarrow 0,85 \times 10^{-6} \mathrm{~A}$ \\
\cline { 2 - 3 } & $0,6 \mathrm{~V}$ & $17 \rightarrow 0,85 \times 10^{-6} \mathrm{~A}$ \\
\cline { 2 - 3 } & $0,6 \mathrm{~V}$ & $17 \rightarrow 0,85 \times 10^{-6} \mathrm{~A}$ \\
\hline
\end{tabular}

Table 6. Resistivity $(\rho)$ and Conductivity $(\sigma)$ for $\mathrm{C}$ (Charcoal)

\begin{tabular}{|c|c|c|}
\hline $\mathrm{V}_{\text {power suplly }}$ & $\rho(\Omega \mathrm{m})$ & $\sigma(/ \Omega \mathrm{m})$ \\
\hline \multirow{3}{*}{$6 \mathrm{~V}$} & 104,876 & $9,54 \times 10^{-6}$ \\
\cline { 2 - 3 } & 104,876 & $9,54 \times 10^{-6}$ \\
\cline { 2 - 3 } & 104,876 & $9,54 \times 10^{-6}$ \\
\hline \multirow{3}{*}{$6,6 \mathrm{~V}$} & $83.900,80$ & $1,19 \times 10^{-5}$ \\
\cline { 2 - 3 } & $83.900,80$ & $1,19 \times 10^{-5}$ \\
\cline { 2 - 3 } & $55.933,87$ & $1,78 \times 10^{-5}$ \\
\hline \multirow{3}{*}{$7 \mathrm{~V}$} & $74.030,12$ & $1,35 \times 10^{-5}$ \\
\cline { 2 - 3 } & 78.657 & $1,27 \times 10^{-5}$ \\
\cline { 2 - 3 } & 78.657 & $1,27 \times 10^{-5}$ \\
\hline
\end{tabular}

\subsection{Resistivity of Thick Sheet Sample}

Resistivity of bulk sample $(\mathrm{t}<\mathrm{s})$ with $\mathrm{t}=1.1 \mathrm{~cm}$ and $\mathrm{s}=1.82$ $\mathrm{cm}$. The material used is $\mathrm{CaCO}_{3}$ (chalk). On the data result, it is seen the measurement result of current (I) and voltage (V), then the result of resistivity and conductivity of the material are presented as well.

Table 7. The Measurement of Current (I) and Voltage (V) for $\mathrm{C}$ (Charcoal)

\begin{tabular}{|c|c|c|}
\hline \multirow{3}{*}{$\mathrm{V}_{\text {power suplly }}$} & $\begin{array}{c}\mathrm{V} \text { (Volt) } \\
\pm \frac{0,4}{10} \times 10 \mathrm{~V}\end{array}$ & $\begin{array}{c}\mathrm{I} \text { (Ampere) } \\
\pm \frac{90}{\mathbf{5 0}} \times 2.5 \mu \mathrm{A}\end{array}$ \\
\hline \multirow{3}{*}{$6 \mathrm{~V}$} & $0,4 \mathrm{~V}$ & $10 \rightarrow 0,5 \times 10^{-6} \mathrm{~A}$ \\
\cline { 2 - 3 } & $0,4 \mathrm{~V}$ & $9 \rightarrow 4,45 \times 10^{-6} \mathrm{~A}$ \\
\cline { 2 - 3 } & $0,4 \mathrm{~V}$ & $9 \rightarrow 0,45 \times 10^{-6} \mathrm{~A}$ \\
\hline \multirow{3}{*}{$6,6 \mathrm{~V}$} & $0,4 \mathrm{~V}$ & $8 \rightarrow 0,4 \times 10^{-6} \mathrm{~A}$ \\
\cline { 2 - 3 } & $0,6 \mathrm{~V}$ & $7 \rightarrow 0,35 \times 10^{-6} \mathrm{~A}$ \\
\cline { 2 - 3 } $7 \mathrm{~V}$ & $0,4 \mathrm{~V}$ & $9 \rightarrow 0,45 \times 10^{-6} \mathrm{~A}$ \\
\hline \multirow{3}{*}{$7 \mathrm{~V}$} & $0,6 \mathrm{~V}$ & $9 \rightarrow 0,45 \times 10^{-6} \mathrm{~A}$ \\
\cline { 2 - 3 } & $0,6 \mathrm{~V}$ & $8 \rightarrow 0,4 \times 10^{-6} \mathrm{~A}$ \\
\cline { 2 - 3 } & $0,6 \mathrm{~V}$ & $8 \rightarrow 0,4 \times 10^{-6} \mathrm{~A}$ \\
\hline
\end{tabular}

Tabel 8. Resistivity $(\rho)$ and Conductivity $(\sigma)$ for C (Charcoal)

\begin{tabular}{|c|c|c|}
\hline $\mathrm{V}_{\text {power suplly }}$ & $\rho(\Omega \mathrm{m})$ & $\sigma(\Omega \mathrm{m})$ \\
\hline \multirow{3}{*}{$6 \mathrm{~V}$} & 39864,55 & $2,5 \times 10^{-5}$ \\
\cline { 2 - 3 } & $44.293,94$ & $2,26 \times 10^{-5}$ \\
\cline { 2 - 3 } & $44,293,94$ & $2,26 \times 10^{-5}$ \\
\hline \multirow{3}{*}{$6,6 \mathrm{~V}$} & $49.830,68$ & $2,00 \times 10^{-5}$ \\
\cline { 2 - 3 } & $85.424,03$ & $1,17 \times 10^{-5}$ \\
\cline { 2 - 3 } $7 \mathrm{~V}$ & $44.293,94$ & $2,25 \times 10^{-5}$ \\
\hline & $66.440,92$ & $1,50 \times 10^{-5}$ \\
\cline { 2 - 3 } & $74.746,03$ & $1,34 \times 10^{-5}$ \\
\cline { 2 - 3 } & $74.746,03$ & $1,34 \times 10^{-5}$ \\
\hline
\end{tabular}

Type resistance (resistivity) is a resistance of a conductor of which the length is one unit of length and area. In international standard, type resistance is a resistance of a conductor of which lengths are $1 \mathrm{~m}$ and 1 $\mathrm{m} 2$, so the unit of type resistance is ohmmeter. Electric conductivity is a measure of the ability of a material to be a conductor of electric current. If an electrical potential object is placed at the ends of a conductor, its moving charge will move and generate electric current. 
Based on the data displaying the measurement of resistivity and conductivity of bulk sample of $\mathrm{CaCO}_{3}$ (white chalk) with 6.6 Volt of voltage, the resistivity values are large; one of them is $596.6 \Omega \mathrm{m}$ with $1.76 \mathrm{x}$ $10^{-3} / \Omega \mathrm{m}$ of conductivity value. Meanwhile, one of the small resistivity values on 6 Volt of voltage variation is $190.9 \Omega \mathrm{m}$ with $5.24 \times 10^{-3} / \Omega \mathrm{m}$ of conductivity value. The measurement of resistivity and conductivity of the thick sheet sample shows large resistivity values with 7 Volt of voltage variation; one of them is $21744.29 \Omega \mathrm{m}$ with $4.59 \times 10^{-5} / \Omega \mathrm{m}$ of conductivity value. Meanwhile, the small resistivity value is $10192.64 \Omega \mathrm{m}$ with $9.81 \mathrm{x}$ $10^{-5} / \Omega$ m of conductivity value.

Resistivity and conductivity value of bulk sample of $\mathrm{C}$ (charcoal) shows a large resistivity value in 6 Volt of voltage variation is $104876 \Omega \mathrm{m}$ with conductivity value is $9.54 \times 10^{-6} \Omega \mathrm{m}$. Meanwhile, the smallest resistivity value in 7 Volt of voltage variation is $74030.12 \Omega \mathrm{m}$ with $1.35 \times 10^{-5} / \Omega \mathrm{m}$ of conductivity value. For thick sheet sample, the large resistivity value in 7 Volt of voltage variation is $746.03 \Omega \mathrm{m}$ with $1.34 \times 10^{-5} / \Omega \mathrm{m}$ of conductivity value. Meanwhile, the small resistivity value in 6 Volt of voltage variation is $39864.55 \Omega \mathrm{m}$ with $2.5 \times 10^{-5} / \Omega \mathrm{m}$ of conductivity value.

Based on the data above, the result that is in line with conductivity theory states that resistivity is inversely proportional with conductivity.

\section{Conclussion}

Based on the research result, it can be concluded that:

1. Four-Point Probe Method is the right method to measure the resistivity and conductivity of a material.

2. Resistivity value of bulk ( $>$ s) for $\mathrm{CaCO}_{3}$ (white chalk) is smaller than thick sheet $(\mathrm{t}<\mathrm{s})$.

3. Conductivity value of bulk for $\mathrm{CaCO}_{3}$ is smaller than thick sheet.

4. Resistivity of bulk ( $\mathrm{t}>\mathrm{s}$ ) for $\mathrm{C}$ (charcoal) is larger than thick sheet $(\mathrm{t}<\mathrm{s})$.

5. Conductivity value of bulk ( $\mathrm{t}>\mathrm{s}$ ) for $\mathrm{C}$ (charcoal) is larger than thick sheet $(\mathrm{t}<\mathrm{s})$.

6. Conductivity is inversely proportional than resistivity.

\section{References}

1. J. Chan, 1994. Four-Point-Probes modify by Friedberg, P., 2002, EECS Microfabrication Technology, dalam http://www inst.eecs.berkeley.edu/ ee143/fa10/lab/four_point probe.pdf, diunduh tanggal 12 Maret 2014.

2. A. Kalavagunta, R. A. Weller, 2005. Accurate Geometry Factor Estimation for the Four Point Probe Method using COMSOL Multiphysics, Excerpt from the Proceedings of the COMSOL Multiphysics User's Conference, Boston.

3. Abdullah, M.H., 1990. Sifat dan kegunaan Semikonduktor, DBP, Selangor.

4. http://id.scribd.com/doc/96942447/Laporan-Fisika Laboratorium-Geofisika-Fisika-Batuan-1.html http://id.scribd.com/doc/59344799/Bab-2.html

5. D. H. Petersen, R. Lin, T. M. Hansen, E. Rosseel, W. Vandervorst, C. Markvardsen, D. Kjær, and P. F. Nielsen, 2008. Comparative Study Of Size Dependent Four-Point Probe Sheet Resistance Measurement On Laser Annealed Ultra-Shallow Junctions, J. Vac. Sci. Technol. B 26, 362. 